\title{
Mathematics Discourse in Instruction (MDI): A Discursive Resource as Boundary Object Across Practices
}

\author{
Jill Adler
}

\begin{abstract}
Linked research and development forms the central pillar of the Wits Maths Connect Secondary (WMCS), a project working with secondary mathematics teachers in one province in South Africa. A key outcome is a sociocultural analytic framework - a discursive resource that has been developed and refined through our work in and across three inter-linked practices. Named Mathematics Discourse in Instruction (MDI), we have used the framework as a planning and reflection tool in professional development and we have operationalised it as an analytic framework for research. MDI enables a description of mathematics made available to learn in a lesson, and an interpretation of shifts in practice across lessons and over time. MDI is both process and product of the WMCS. I describe and reflect on our use of MDI to build a case for embracing a discursive resource as a boundary object that moves productively across multiple practices.
\end{abstract}

Keywords Mathematics teaching - Professional development - Boundary object

\section{Introduction}

Since 2010, I have been working on the Wits Maths Connect Secondary (WMCS) project, the goal of which is to improve the teaching and learning of mathematics in secondary schools in one province in South Africa through the professional development of mathematics teachers. We hope to contribute to strengthening the mathematics pipeline within the secondary school and between school and tertiary mathematics studies. Over time we have come to focus in on grades 9 and 10 - a critical transition point in mathematics education in the country.

Hans Freudenthal award.

\footnotetext{
J. Adler $(\bowtie)$

University of the Witwatersrand, Johannesburg, South Africa

e-mail: jill.adler@wits.ac.za

(C) The Author(s) 2017

G. Kaiser (ed.), Proceedings of the 13th International Congress on Mathematical

Education, ICME-13 Monographs, DOI 10.1007/978-3-319-62597-3_9
} 
The major intervention that evolved over the first three years of the project, and that has continued to strengthen, is a Mathematics for Teaching course, called Transition Maths (TM), complemented by a local version of Lesson Study. The intervention thus works with teachers on their mathematical knowledge for teaching away from the school (the TM course is offered at the University), and then on their mathematics teaching practices in the school (the Lesson Study work takes place at schools organized in clusters and in the afternoons). The attraction and excitement of this work is that it deliberately links research and development. In the South African context, and I suspect elsewhere, it is not usual that both research and development activities are supported by funding from the National Research Foundation. As a linked research and development project, we have been researching improvement in knowing, teaching and learning mathematics, in relation to the project interventions. Of course, this required elaboration of what counts as improvement in mathematical knowledge for teaching, in mathematics teaching and learning, and how we would describe and interpret each of these.

What was needed for this work was a framework for describing mathematics teaching, interpreting shifts in practice and supporting the development of mathematics teaching practices. The framework we have developed is called Mathematics Discourse in Instruction (MDI), so named to foreground concern with the quality of mathematics made available to learn in school, and that we were working with teachers on their instructional practices. MDI has become a unifying framework in the project, operating as a boundary object across professional development and research activities. MDI frames our work in our course sessions, and our lesson study work; and it has been operationalised for research.

This paper is focused on the MDI framework, what led to its development, the form it has taken and why, and how it is used across our teaching and research practices. I will share with you the role and nature of MDI as a boundary object. I hope to convince you of the power of the framework. It is a living framework, with power lying in its iterative nature, moving between and supporting both our research and development work.

\section{The Context}

In 2009, the First Rand Foundation (FRF - the foundation of a major bank in South Africa), in partnership with the national Department of Science and Technology (DST) and National Research Foundation (NRF) launched the Maths Education Chairs Initiative project, with ambitious goals and five years of funding to support proposals for research-linked development work that would:

- improve the quality of mathematics teaching in previously disadvantaged secondary schools;

- improve mathematics results on national examinations (pass rates and quality of passes) through quality teaching and learning;

- research sustainable and practical solutions to the mathematics crisis;

- develop research capacity in mathematics education;

- provide leadership and increase dialogue around solutions. 
Personally, this came as an opportunity to put to work what I had learned over the previous two decades in the academy and in mathematics teacher education. In all my research work, I have focused on problems of practice, moving from the challenges of teaching mathematics in multilingual classrooms to the challenges of describing and theorising mathematical knowledge in and for teaching, in a context where the majority of teachers were statutorially undereducated mathematically in apartheid teacher training colleages. The FRF/DST/NRF funding was an opportunity for me to shift my research from its impetus in problems of practice, to research-informed-development and development-informed-research - an opportunity to deliberately engage in a process where research, school mathematics teaching and teacher education were able to speak to (listen and hear) each other.

Simply, I saw this as an opportunity put research in the service of teaching, and moreover, of teaching in schools and classrooms for 'historically disadvantaged' students. This is important in our field, for as Skovsmose so aptly conjectured in his talk at the ICMI Centennial conference in Rome in 2008: "90\% of research in mathematics education concentrates on the $10 \%$ of the most affluent classroom environments in the world, while $10 \%$ of the research addresses the remaining $90 \%$ of the classrooms" (Skovsmose, 2011, p. 18). The classrooms I would be working in were squarely located in the "remaining 90\%" of relatively impoverished schools.

So, what is this context? It is beyond the scope of this paper to present a full description of the South African mathematics education context, some twenty years post-apartheid. Interested readers are referred to a detailed elaboration of this in Adler and Pillay (2017). In brief, high levels of poverty and inequality endure. The relationship between poverty and educational outcomes is well known, and starkly reflected in poor educational outcomes for the majority of school learners, particularly in mathematics. While over $90 \%$ of all students up to 16 years are in school, inequality prevails, with socio-economic status being its most significant determinant. The performance curve in national assessments at both Grade 9 and Grade 12 levels is grossly skewed, with the majority of learners performing poorly in mathematics. The system is slowly improving, with 2015 TIMSS results indicating we have moved from "very low" in 2003 to "low" performance (Reddy et al., 2016). However, there remains a disjuncture between institutional and epistemic access (Morrow, 2007). Most students are in school, but only a minority have access to quality education.

In carving out our intervention we were motivated firstly by the understanding that it is precisely in conditions of poverty that the quality of instruction in schools matters, and thus its improvement is an imperative for social justice (Gamoran \& Long, 2006). Secondly, also a social justice issue, we hoped to take up the challenge of investigating the research-development nexus in mathematics education in under-researched poorly resourced conditions-or what Shalem and Hoadley (2009) refer to as "schools for the poor".

Shalem \& Hoadley (op cit) described the dual economy of schooling in South Africa, providing critical insight into the impact of different economic conditions on teachers' work. Teachers who work in "schools for the poor" do not have access to educational "assets" taken-for-granted in schools for the middle classes. Not only 
are infrastructural conditions poor, but knowledge resources both human and material (Adler, 2012a) are typically limited; and many students in such schools are not academically prepared for the grade they are in. Unsurprisingly teachers suffer from low morale. Added to the emotional and material challenges of their work, South African teachers in underperforming, poor schools face highly prescriptive curricula, national testing and a culture of bureaucratic compliance, all enacted with the goal of improving national schooling outcomes. Shalem \& Hoadley argue that this combination of demands makes teachers' work in schools for the poor "impossible".

In the first year of the project we set out to learn in and from the schools. Diagnostic testing of students, informal conversations with teachers, and observation of lessons across a range of grade levels together confirmed Shalem \& Hoadley's general analysis. Learner error in basic algebra, for example, was extensive, and basic resources like textbooks were not always available. More specifically, mathematics lessons were characteristically incoherent: while students might have been 'working' (listening to the teacher, writing in their notebooks), the mathematics they were to be learning was, in our terms, "out of focus" (Adler, 2012b). Our research and development work, and particularly how we were to frame it, had to be grounded in these realities and take cognisance of the conditions of teachers' work.

\section{Our Framework-Mathematics Discourse in Instruction}

Making sense of the mathematics teaching and learning practices we observed necessarily brings ways of thinking about such practices to the fore, and we surveyed the field of mathematics education research in search of frameworks that could help us describe our pedagogic range. Our field, over time and in different ways, has helped us to distinguish between instruction focused on rules without reasons (Skemp, 1987), on procedures without rationales (Artigue, 2009). Frameworks for describing mathematics teaching, for example, LMTP (2011). Mathematical Quality of Instruction (MQI) have been developed. Using this range of theoretical and analytic resources, we we could easily describe almost all the lessons we observed as rule bound and procedural. But the lessons were not all of the same quality in terms of opportunities made available to learn mathematics. Using more elaborate and refined frameworks like MQI, while more illuminating nevertheless would have resulted in homogenising all our teachers and their instructional practices. LMTP (2011) Mathematical Quality of Instruction incorporates features like lesson format and links to learning alongside teachers' mathematical talk. We needed a framework that was more sensitive to formalist (typically referred to as "traditional") orienations to knowledge (Guthrie, 2011). The framework needed to work with our empirical field, and so be responsive to existing teaching practices, and disaggregating within and across these. Finally, we also needed a framework that would enable us to work with a developmental 
trajectory, guiding our intervention work and enabling a description of shifts in instructional practice, and so in terms of mathematics made available to learn.

Our framework, MDI, or Mathematics Discourse in Instruction, is represented in Fig. 1. It has its roots in sociocultural theory, particularly Vygotsky's (1978) theory of mediated learning, and scientific knowledge as a network of connected concepts. Our starting point is that teaching and so learning is always about something, and bringing that into focus is the teacher's work. Following variation theorists (Marton \& Tsui, 2004) we call this 'something' the "object of learning"- - that which students are to know and be able to do. In practical terms, it is akin to a lesson goal, but worded so that the mathematics of the goal needs to be made clear. Whatever the mathematical goal, or 'object', it needs to be mediated and so exemplified and elaborated. Figure 1 shows that exemplification (through examples and tasks), explanatory talk (in how signs and objects are named, and justified or legitimated), and learner participation are viewed as the key mediational means or cultural tools in mathematics classroom instruction. We hold that this is the case in any classroom, whatever the pedagogy or view of knowledge. However, this framing enables us to stay close to what it was we saw teachers doing. In all lessons, 'examples' were offered, embedded in various tasks, though typically procedural in nature. Communication then proceeded in the lesson, with words used to name the mathematics being talked about and to build explanations of, or legitimate what was to be known and done. And learners were invited to participate in this communication, even if it was all or mostly in the form of listening to the teacher.

As noted earlier, we use MDI to plan our sessions in the TM1 course; in our Lesson Study work to guide planning and reflection on lessons; and we use it for our research on mathematics teaching. Given our socio-cultural orientation, as we move across these practices, so we understand, and indeed expect that the framework will operate in different ways, shaped by the social practice we are working in. As I also mentioned earlier, MDI is a living framework, with power lying in its iterative nature, moving between and supporting both our research and development work.

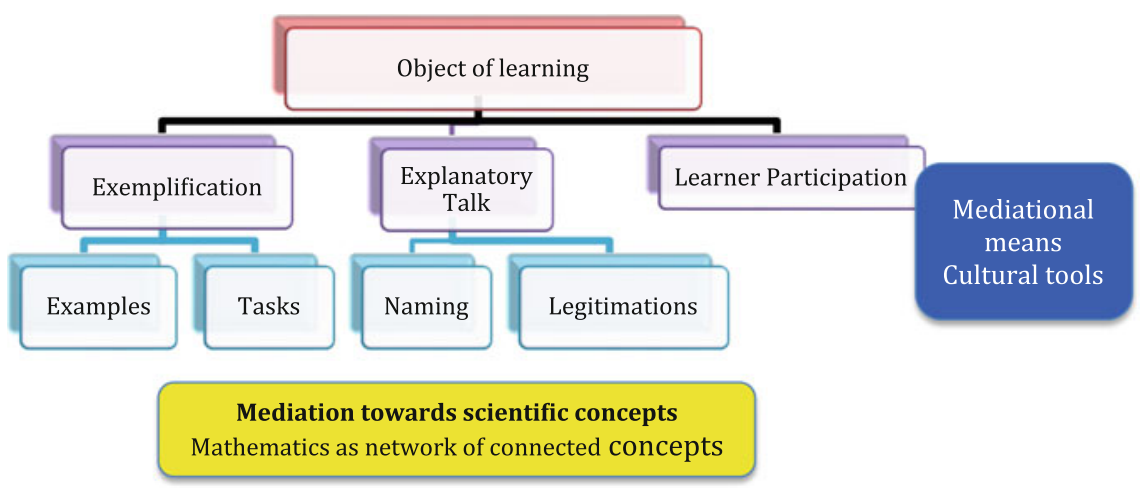

Fig. 1 Constitutive elements of MDI (Adapted from Adler \& Ronda, 2015) 
We have learned a great deal over the past six years, from how to responsively and responsibly describe practice (Adler \& Ronda, 2017b; Adler \& Venkat, 2014; Venkat \& Adler, 2012) and differences in practice (Adler \& Ronda, 2015), all using the MDI as analytic framework. We have put MDI productively to work in the practice of Lesson Study (Adler \& Ronda, 2017a) and have reported the promising results on the impact of our professional development intervention on student attainment (Pournara, Hodgen, Adler, \& Pillay, 2015). In the remainder of this paper, I illustrate our use of MDI across these practices.

\section{Doing Our Research: Describing Teaching and Interpreting Shifts in Practice}

A major task for any lesson analysis is how to chunk or divide the lesson into analytic units. In our analysis, we first need to infer the lesson goal, or object of learning, as this is key to our analysis, and we then proceed to chunk the lesson into what we call mathematical episodes. We begin by watching the video-recording and simultaneously (re)reading the transcript to identify the intended object of learning that we know is not synonymous with what is enacted (Marton \& Tsui, 2004). We look for what is announced in some way, typically by the teacher at the start of the lesson, often stated as a topic or written on the board. For example, in one of our lessons, Mutliplying Algebraic Expressions was written on the board, at the same time as the teacher said, "Today we are going to learn to multiply expressions". The intended object of learning was carrying out a procedure for different products, which as it transpired in the lesson included two or more monomials; a monomial and binomial; and then two binomials. We then chunk the lesson transcript into mathematical episodes that are identified by a shift in focus of attention with respect to content, typically marked by a task that encompasses selected example(s), and bears some relation to the stated object of learning. We identify a next episode by the introduction of a new task and focus on a new example. This chunking produces a number of episodes, and again by way of example in this particular lesson, Episode 1 focused on multiplying single terms, paying attention to laws of exponents. Episode 2 was marked by the shift to the product of a monomial and binomial, and so on. We then examine each episode for its exemplification, explanatory communication and learner participation.

Table 1 provides a summary of how we have categorised key elements of MDI. It is beyond the scope here to discuss each of these in detail. I will focus only on examples and legitimating criteria so as to communicate how our analysis works to describe what is made available to learn in a lesson or set of lessons through the set of examples offered, and the criteria for what is to count as mathematics are communicated.There is more detail on each of these and the remaining elements in Adler and Ronda (2015, 2017b). 


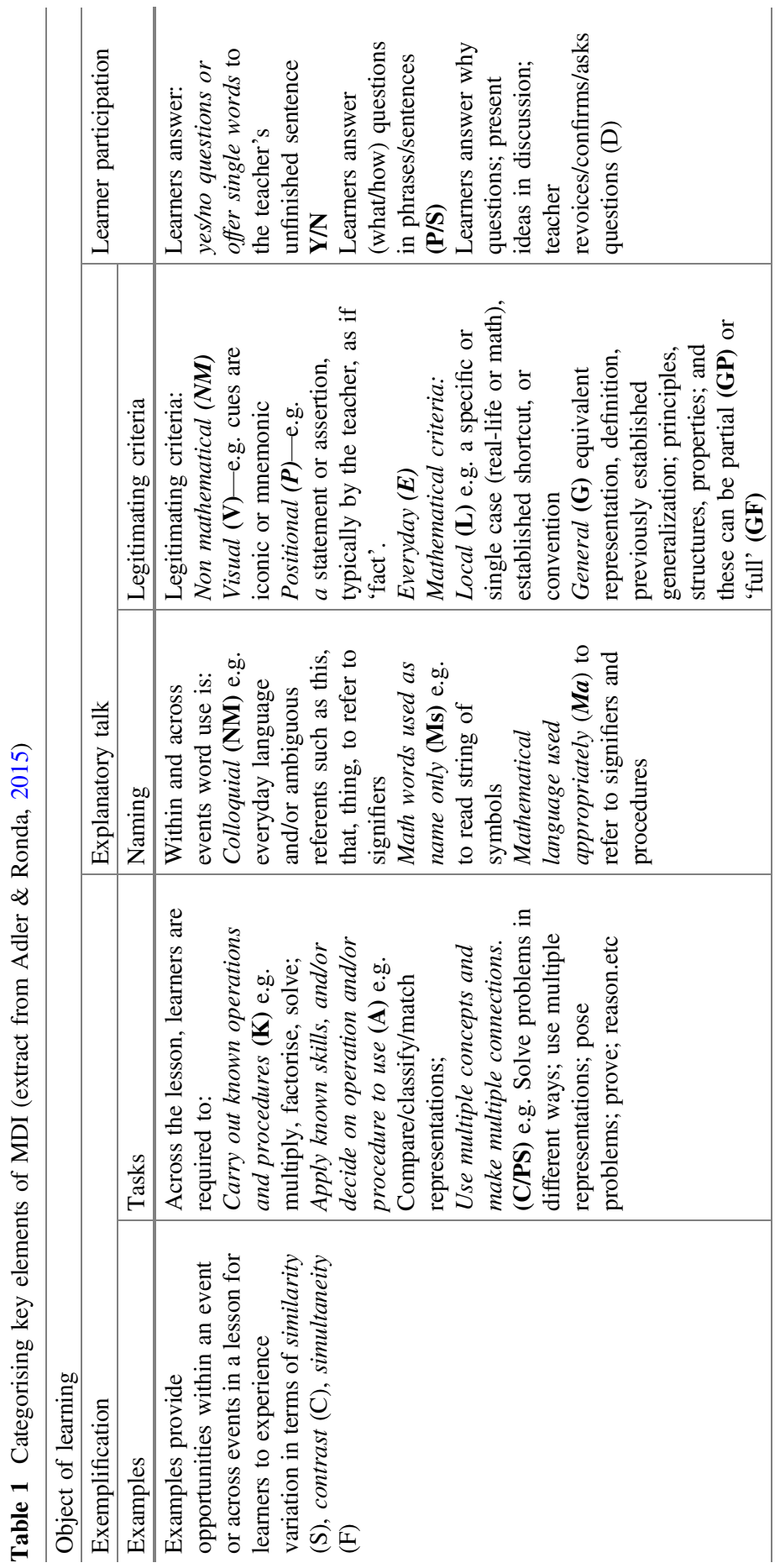


For examples, we are interested in their selection and sequencing and how these accumulate within and across episodes. We draw on the work of Watson and Mason (2006), who in turn draw on Marton and Tsui (2004) to describe movement towards generality across a sequence of examples. If a set of examples brings attention to similarity across examples, and so to that which is invariant, this offers opportunity to generalise. If a set of examples brings attention contrast, and so what something is in relation to what it is not, or to a different class, opportunities are made available to recognise boundaries between classes of examples, and so further generalise. When more than one aspect of an object of learning are fused, with simultaneous variance/invariace across an example set, generalisation is further enhanced.

Of course, in school mathematics lessons, an object of learning could also be a particular procedure. While in many cases, the same procedure would be carried out on different examples (say of solving linear equations), there are also possibilities for a lesson to focus on different procedures or strategies for finding the solution to the same equation. Here, similarity is in the invariance in the solution or answer. So too with different strategies for solving one complex problem. We thus extended our notion of exemplification to include particular procedures or strategies for solving a problem if it is these in focus in the lesson.

Of course, examples are embedded in tasks and while I do not elaborate this here, as will be seen below, these vary in cognitive demand, and this is important to capture across a lesson. Moreover, examples and tasks don't speak for themselves, hence our attention to the accompanying explanatory talk. I focus on what we refer to as legitimating criteria within the classroom, and particularly the teacher's talk.

In previous research on pedagogic discourse in teacher education (e.g. Adler \& Davis, 2011), we identified different domains of knowledge appealed to so as to legitimate what counted as mathematics: the domain of mathematics itself; non-mathematical domains e.g. everyday knowledge; the curriculum; and the authority of the teacher. Work in school classrooms led to elaboration of the mathematical domain, and distinctions between criteria related to properties of mathematical objects, to accepted conventions and derived procedures, to instances or empirical cases, and then to the general case or proof (Adler, 2012a). As we worked with the WMCS data, we maintained some and then elaborated other distinctions: criteria of what counts (or not) as mathematical that are particular or localized (e.g. a specific or single case, an established shortcut, or a convention) from those that have generality (e.g. equivalent representation, definition, previously established generalization; principles, structures, properties) and also further distinguished partial from full generality. We remained interested in non-mathematical criteria, everyday knowledge or experience (e.g. the shape of an open crocodile's mouth as determinant of the direction of the inequality sign), visual cues as to how a step, answer or process 'looks' (e.g. a 'smile' as indicating a parabola graph with a minimum); or memory devices that aid recall (e.g. FOIL); or when what counts is simply stated, thus assigning authority to the position of the speaker, typically the teacher. 
These varying criteria open or close opportunities for learning. At one extreme are legitimations based on principles of mathematics, with varying degrees of generality, and possibilities for learners to reproduce or reformulate what they have learned in similar and different settings. At the other end are appeals to the authority of the teacher or visual cues that produce a dependency on the teacher, on memory (this is what you must do); or on how things 'look'. Such imitations, while a necessary part of learning (Sfard, 2008; Vygotsky, 1978), cannot be the endpoint of learning. The criteria for what counts as mathematics that emerge over time in a lesson are key to being able to describe what is made available to learn.

Once we have categorised each episode, we then need to make judgments as to how the range of examples and legitimating criteria for mathematics accumulate through the lesson. Table 2 summarises our summative judgments within categories and across a lesson in terms of levels for examples and explanatory talk. The assignment of a level in our analysis is an interpretive judgment, reflecting our privileging of generality through exemplification and principled criteria as these unfold over a lesson. However, these are ultimate goals, and there is fluid movement between categories. For example, a summative judgment as a 'higher' level of legitimation depends on movement across non-mathematical, local and more general criteria in the lesson, as elaborated in Adler and Ronda (2015).

With these categories and levels of judgment we are able to look across teachers who have participated in our TM course. We were interested to see whether strengthening teachers mathematical knowledge for teaching, particularly through the course and so away from the school, and with minimal in school support through initial lesson study work, correlated with shifts in their mathematics teaching in what ways and how. We have studied pre and post lessons of ten TM teachers who completed the course in 2012. Table 3 presents the summary of our analysis across the ten teachers, after analysis and categorisation of episodes in each lesson, and then a summative judgment using of each category.

Detailed presentation of this data and its analysis is in Adler and Ronda (in preparation) where we also explain the sample of the ten teachers. There were 18 teachers in the 2012 cohort, and for various reasons were not able to follow all through to 2013. For example, some did not complete the course; others had moved schools and were no longer accessible.

Included in the participation in the TM course was an entry test-a mathematics pre-test, used to discern what strength of mathematical knowledge each was bringing, and so orient our initial sessions. We also used this to counsel teachers at the extreme ends of attainment out of participation. Teachers were also tested at the end of the course. Testing teachers is a contested practices outside of formal course work and we have discussed and reflected on our usage of this elsewhere (Adler, $2012 \mathrm{~b}$ ). As it turned out, the ten teachers remaining in our video study formed an interesting bifurcation. The first five teachers entered the course with relatively low attainment in the initial test, and while the post test showed improvement for some of these, the scores obtained were below the threshold we had set as a marker of competence with at least Grade 10 level mathematics. The second set of five 
Table 2 Summative judgments for interpreting examples and explanatory talk extracted from Adler \& Ronda, in Adler and Sfard (2017)

\begin{tabular}{|c|c|c|}
\hline Examples & Naming & Legitimating criteria \\
\hline $\begin{array}{l}\text { The set of examples provide } \\
\text { opportunities in the lesson } \\
\text { for learners to experience: } \\
\text { Level 1: one form of } \\
\text { variation i.e. similarity or } \\
\text { contrast } \\
\text { Level 2: at least two forms } \\
\text { of variation: } \mathbf{S} \text { and S OR S } \\
\text { and C } \\
\text { Level 3: simultaneous } \\
\text { variation (fusion) of more } \\
\text { than one aspect of the object } \\
\text { of learning and connected } \\
\text { with similarity and contrast } \\
\text { within the example set. (S, } \\
\mathbf{C}, \mathbf{F} \text { ) } \\
\text { Level } \mathbf{0} \text { : simultaneous } \\
\text { variation with no attention to } \\
\text { similarity and/or contrast }\end{array}$ & $\begin{array}{l}\text { Use of colloquial and } \\
\text { mathematical words within } \\
\text { and across episodes is: } \\
\text { Level 1: talk is colloquial or } \\
\text { non-mathematical (NM) e.g. } \\
\text { everyday language and/or } \\
\text { ambiguous pronouns such as } \\
\text { this, that, thing, to refer to } \\
\text { what is being written or } \\
\text { pointed at; where } \\
\text { Mathematical words are } \\
\text { used, these are as names } \\
\text { labels or to read a string of } \\
\text { symbols (Ms) } \\
\text { Level 2: movement between } \\
\text { NM and (Ms) and some } \\
\text { mathematical language used } \\
\text { appropriately (Ma) to refer } \\
\text { to other words, symbols, } \\
\text { images, procedures } \\
\text { Level 3: movement between } \\
\text { colloquial NM and formal } \\
\text { math talk Ma }\end{array}$ & $\begin{array}{l}\text { Criteria for what counts as } \\
\text { mathematics that emerge } \\
\text { over time in a lesson and } \\
\text { provide opportunity for } \\
\text { learning geared towards } \\
\text { scientific concepts } \\
\text { Level 0: all criteria are non } \\
\text { mathematical (NM) and so } \\
\text { either Visual (V) - e.g. cues } \\
\text { are iconic or mnemonic; or } \\
\text { Positional (P) - e.g. } \\
\text { a statement or assertion, } \\
\text { typically by the teacher, as if } \\
\text { 'fact' or Everyday (E) } \\
\text { Level 1: criteria include } \\
\text { Local (L) e.g. a specific or } \\
\text { single case (real-life or } \\
\text { math), established shortcut, } \\
\text { or convention } \\
\text { Level 2: criteria extend } \\
\text { beyond non mathematical } \\
\text { and L to include Generality, } \\
\text { but this is partial GP } \\
\text { Level 3: GF math } \\
\text { legitimation of a concept or } \\
\text { procedure is principled } \\
\text { and/or derived/proved }\end{array}$ \\
\hline
\end{tabular}

Table 3 MDI of ten teachers in 2012 and 2013

\begin{tabular}{|c|c|c|c|c|c|c|c|c|c|c|}
\hline \multirow{3}{*}{$\begin{array}{l}\text { Trs } \\
\text { Year }\end{array}$} & \multicolumn{4}{|c|}{ Exemplifying } & \multicolumn{4}{|c|}{ Explanatory talk } & \multirow{2}{*}{\multicolumn{2}{|c|}{\begin{tabular}{|l} 
Learner \\
P'cipation
\end{tabular}}} \\
\hline & \multicolumn{2}{|c|}{ Examples } & \multicolumn{2}{|l|}{ Tasks } & \multicolumn{2}{|c|}{ Naming } & \multicolumn{2}{|c|}{ Legitimating } & & \\
\hline & 2012 & 2013 & 2012 & 2013 & 2012 & 2013 & 2012 & 2013 & 2012 & 2013 \\
\hline 1 & L1 & L1 & L1 & L2 & L2 & L2 & L0 & L0 & L2 & L1 \\
\hline 2 & L2 & $\mathbf{L 3}$ & L2-L1 & L2-L1 & L2 & L2 & L0 & L0 & L1 & L1 \\
\hline 3 & L2 & L1 & L1 & L1 & L2 & L2 & L0 & L0 & L1 & L1 \\
\hline 4 & L1 & $\mathbf{L 3}$ & L1 & L2-L1 & L2 & L2 & L1 & L1 & L1 & L1 \\
\hline 5 & L1 & L3 & L2-L1 & L2-L1 & L2 & L2 & L0 & L1 & L1 & L1 \\
\hline 6 & L1 & $\mathbf{L 3}$ & L1 & L2-L1 & L2 & L3 & L0 & L2 & L2 & L1 \\
\hline 7 & L1 & $\mathbf{L 3}$ & L2-L1 & L2-L1 & L2 & L2 & L2 & L2 & L2 & L1 \\
\hline 8 & L2 & L2 & L2-L1 & L1 & L2 & L3 & L1 & L3 & L2 & L1 \\
\hline 9 & L2 & $\mathbf{L 3}$ & L2 & L2-L1 & L2 & L2 & L0? & L3 & L3 & L3 \\
\hline 10 & L2 & $\mathbf{L 3}$ & L2-L1 & L2 & L2 & L2 & L1 & L1 & L2 & L3 \\
\hline
\end{tabular}


teachers (so teachers 6-10 in Table 3), all exited the course with relatively high attainment, with most starting with better scores than teachers 1-5.

What we see if we focus in on the examples column, is that there was improvement in the example sets of most teachers. All ten teachers' example sets in their 2012 lesson were judged to be either at levels 1 or 2. In 2013 for seven teachers, this had shifted from either level 1 or 2 to level 3 . We interpret this as a general shift across teachers - that following their participation in the course, their selection and sequencing of examples in their lessons indicated greater opportunity for learning in terms of our criteria of privileging moves towards generality. Looking down the two columns on legitimating talk, we see a different pattern. Firstly in six of the 10 teachers' lessons, judgement of how mathematics was legitimated remained at level 0 , i.e. justifications for procedural steps and or definitions of concepts were non-mathematical: they were either assertions by the teacher, related to everyday knowledge or reliant on visual cues. Three of the first group of teachers' lessons did not progress beyond this in 2013. All five of the second group of teachers lessons were judged as level 2 or 3, and so more principled and moving to greater generality.

Notwithstanding that this paper does not provide access to the how of our categorising of mathematical episodes, nor judgment of levels (readers are referred to other papers referenced above), the point here it that it indicates the power of the MDI framework. By focusing our attention on examples and legitimations I have illustrated that, and to a lesser extent how, the framework disaggregates mediational means. This enables nuanced interpretations of shifts in practice - or what we refer to elsewhere as 'take-up' from the WMCS PD programme (Ntow \& Adler, under review). I remind readers that had we used the MQI framework, for example, the differences between our ten teachers would not have been as visible. Moreover, we can describe practices and shifts in these in terms of what is present, and what it is that can and does shift, even if at surface level, the lessons might appear similar.

It is instructive for us that most teachers in this study expanded their example sets. Our work in lesson study, and further classroom observations we have done confirm this finding. A focus on selection and sequencing of examples, using concepts and ideas from variation theory, and the notion of variation amidst invariance speaks to teachers, and in ways that they can begin to select examples for their lessons differently and more deliberately. In the context of the incoherence we observed in our initial year in the project, this is indeed progress, and also indicative of developmental activities with teachers that have impact. At the same time however, we confront the difficulty most teachers have in developing and strengthening their mathematical talk, and in providing opportunities for their students to appreciate mathematical justification.

And it is here that the bifurcation across the sample of teachers provides for two hypotheses that require further study, but begin to suggest important research on professional development in our field. Working from the easily agreed assumption that different teachers will benefit or learn differently in the same PD offering, we can now hypothesise that for some teachers particular PD is perhaps not beneficial at all. Our experience to date is that teachers whose mathematics is very weak (and 
this is not uncommon in South Africa in cases where teachers are teaching out of field and at levels beyond their training), do not benefit from the ways in which TM is structured and offered. It begins at a level that thwarts traction for some teachers. We could hypothesise then that such might be the case in other forms of PD. Reports on research on professional development in mathematics rarely point to instances of 'failure' in terms of teachers' learning, nor do they suggest how lack of 'take-up' in practice might correlate with, for example, aspects of mathematical knowledge for teaching.

I hope to have at least piqued your interest in the analytic power of MDI, particularly as a tool for research geared towards describing and interpreting differences and so shifts in practice within and across teachers' lessons. In the papers mentioned above, we have also argued that because MDI is grounded in the realities of our classrooms, and because we have identified levels indicating improvement, albeit within a particular view of school mathematics practice, the descriptions and interpretations we produce are not only responsive, but also responsible and developmental. Staying with a focus on exemplification (and examples within this) and explanatory talk (and legitimating criteria within this), I now move on to illustrations of its use in our PD practice, and so its use across practices.

\section{From MDI for Study of Teaching to MDI for Work on Teaching}

I begin with the TM course and select two sessions where the focus was on inequality relations, relations that we have come to understand are generally weakly understood. I use these to illustrate how the elements of MDI inform and are informed by our teaching in the PD. Our concern in the TM course sessions is that participating teachers are provided opportunity to strengthen their mathematical knowledge for teaching. We work on deepening their understanding of concepts, through building their understanding and communication of generality, their appreciation of mathematical structure, as well as their operational or procedural fluency with respect to key concepts or ideas in the secondary curriculum, inequality relations being one of them. To do this we pay deliberate attention to our selection of examples, the tasks these are embedded in, the range of representations we wish teachers to be familiar with, and then how these ideas are talked about, mathematically - the words used, and justifications elaborated.

The first set of example in Fig. 2 are numerical inequality relations, embedded in a task requiring teachers to state whether the inequality was true of false, and then justify their statements. Each of the examples was presented on a separate card. There are important things to notice in the selection and sequencing of these examples where the move first is from 3 to 10 both positive integers to -3 and -10 . This variation enables a focus of attention (of course the lecturer has to draw attention to this) on the changing signs, and what this means for the inequality 
Working with inequalities

(1) Comparing numbers: Look at cards $1-5$

Is the statement on the card true or false?

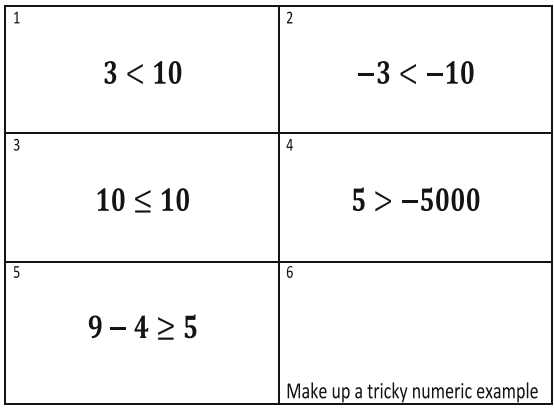

(2) Comparing algebraic expressions: Look at cards $6-10$. Is the statement always true sometimes true or never true?

\begin{tabular}{|c|c|}
\hline$x^{2}>0$ & $-x<0$ \\
\hline$(m-4)^{2}>0$ & $(p+2)^{2}>2$ \\
\hline$p^{2} \leq 0$ & 12 \\
\hline
\end{tabular}

Fig. 2 Extract from TM1 course notes-Session 1 on inequalities

relation. The next card varies one number so that the two numbers related are the same, and the inequality sign is less than or equal to. The remaining cards vary the inequality sign (it is now greater than) as well as the numbers related and their signs. Cards 7-11 introduce a variable, and quadratic inequalities, with the task now requiring teachers to state whether the statements are always, sometimes or never true. The set of examples and their sequencing are focused on properties of the square of any number and its relation to zero, with all examples being of squares in different forms, but the inequality sign changing, as well as the relation to 0 . In each set there is also an 'empty' card (cards 6 and 12) for teachers to contruct their own examples, and so generate relations that the lecturer can use to further exemplify and extend the example set in the session. ${ }^{1}$

The task is not only one of recognition of the relation, but significantly of how to justify this recognition. In this teachers are provided the opportunity build their substantiations and justifications, and mediation in this session by the lecturer (typically by offering counter examples) is on assisting teachers to distinguish partial from full justifications, and how these are expressed (for example, if a justification is based on particular numbers).

The power of the framework in our teaching is that it has enabled us to be deliberate in our work, firstly clarfiying for ourselves our 'objects of learning', and thus what it is we wish to bring into focus with the teachers. Secondly we then attend to the selection of tasks and examples that would best meet our goal. Thirdly we pay attention to what word use entails in a mathematical justification of the tasks set, and how to work on these with teachers, bringing to the fore the mathematical principles at work.

\footnotetext{
${ }^{1}$ Our card activities have been inspired by the work of Malcolm Swann in the UK.
} 
How then might teachers come to use MDI in their own practice? In iterations of the TM course in 2014 and now 2016, we have integrated the mediation of MDI as a teaching tool within the course, as not all participating teachers have been able to participate in our Lesson Study work. We are also interested to see whether and how this kind of mediation supports the planning and reflection on lessons without the intensity of LS cycles. I move on now to share an example of our use of MDI as a resource for planning and reflecting on teaching in one of our LS cycles.

\section{Doing Lesson Study}

As in our teaching the TM course, here too the tool crosses the boundary from research practice, where operationalisation of constructs and their indicators is critical, to more flexible use, bent to the practices in PD and school classrooms. Our LS is driven by the same goals as other LS work were teachers work collaboratively on their practice (e.g. Fernandez, 2002). There are, however, significant adaptations in our LS work, a function of the contexts and constraints of the WMCS project resources. We work with teachers from a cluster of schools, who come together one afternoon a week for three consecutive weeks, in one school. The teachers are thus working with their own or their colleagues' students. Similar to other LS, in week 1 the teachers together with a researcher from the project plan a lesson on a topic selected by the teachers. In week 2 one teacher teaches a class that remains after school hours for this, and others observe. After the lesson, the students leave and reflection and replanning follows. In week 3 , a different teacher teaches a different class, and this too is followed by reflection and replanning and the resulting lesson plan shared.

The lesson planning, and its reflection is structured by MDI, albeit in a different format that has developed with teachers through its use in LS, and referred to as the WMCS Mathematics Teaching Framework. The four elements of MDI (object of learning, exemplification, explanatory talk and learner participation) are visible, with questions to assist planning and reflection. Our intention is that in our collaborative work with teachers, we have a shared language with which to talk about and reflect on practice, and again in ways that is sufficiently close to their daily work (Figs. 3 and 4 ).

The lesson plan above was developed in a LS cycle where the selected topic was the Hyperbola graph (taught in Grade 10 in our schools), with particular focus on the parameters a and $\mathrm{q}$ in the general equation $y=\frac{a}{x}+q$.

Adler and Ronda (2017a) provide a full description of this lesson, and how it informs and is informed by MDI. It was the second lesson in the cycle, and thus the plan below is a revised version of the first lesson, following reflection on the first lesson where the range of examples, their representational forms and the task 
Lesson goal: What do we want learners to know and be able to do?

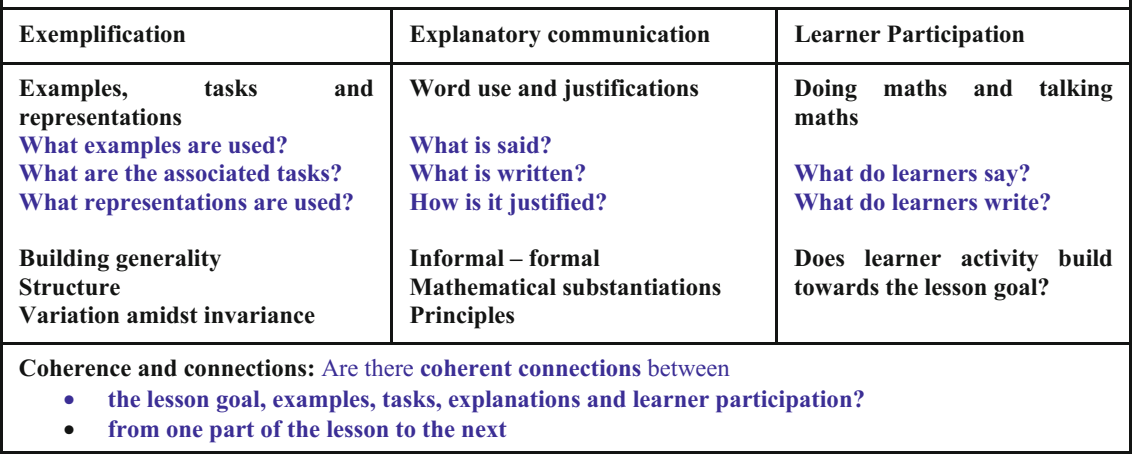

Fig. 3 The WMCS mathematics teaching framework

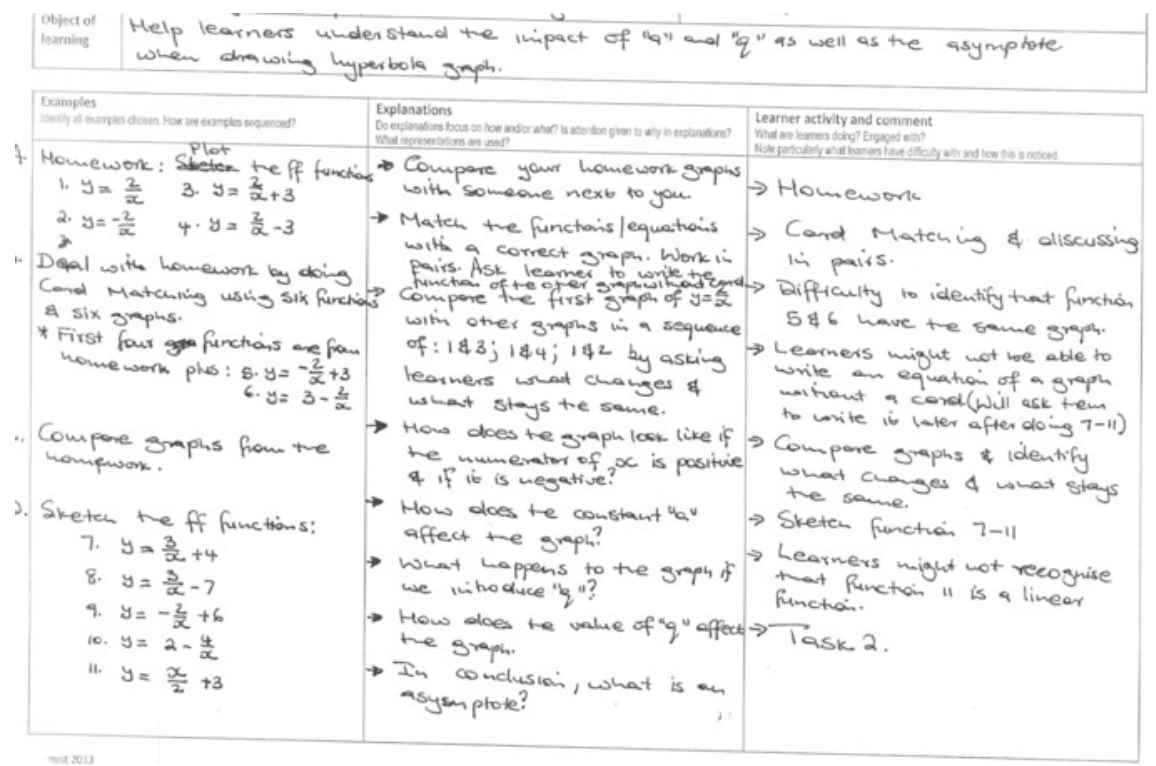

Fig. 4 An example of a lesson plan developed for a LS cycle

demands, together with attention to language use had been discussion. Notice first examples $1-6$ in column 1 where $\frac{2}{x}$ and 3 remain invariant, but signs and operations are varied, as is the order of terms in example 6. The intention of focusing learners' attention on a and q through these variations is clear in the teacher's elaboration of the explanation and learner participation columns. Her goal for students to articulate how the graphs and equations are the same and different, and so build their explanatory communication, is visible in the middle column. 
Our structuring of LS by MDI is instructive and productive, and we are currently in the process of describing our experience and reporting our results in relation to how LS provides a learning space for all participants (the teachers, their students and ourselves as researchers) (Alshwaikh \& Adler, 2017a), and one too where conflicts arise, within and between teachers and researchers in terms of simultaneous commitments to the LS process, teaching and student needs (Alshwaikh \& Adler, 2017b).

\section{MDI-Its Role and Nature as a Boundary Object}

In earlier work on MDI (focused mainly on examples and explanations) we described how we were using this across "researcher and practitioner communities" (Venkat \& Adler, 2013). ${ }^{2}$ We noted our concern to engage with and impact on teachers' 'common-sense discourse' (Brown (1997), cited in Hargreaves (1999)) and thus created "research-based artifacts and designed specifically for trialing in the overlapping 'boundary' region of the communities of research and classroom practice" (Venkat \& Adler, 2013, p. 3). Star and Griesemer (1989) refer to such artifacts as 'boundary objects' that are "plastic enough to adapt to local needs and constraints of the several parties employing them, yet robust enough to maintain a common identity across sites. They are weakly structured in common use, and become strongly structured in individual site use.' (p. 393). In this paper I have shown how we have used the MDI framework across research on teaching, and in the practice of PD and classroom mathematics teaching. I have argued that its 'strong structuring' as a research tool has enabled nuanced disaggregation of elements of practice, and a developmental trajectory for working on teaching. I hope to have also illustrated that as a boundary object, it is iterative in nature, and flexible (strong yet bending). MDI is a living framework that is simultaneously unifying and differentiating in our project. Hence our view that it is powerful.

\section{Concluding Comments}

It is important to end this paper by returning to the context of MDI and its roots. This relates back to introductory comments about educational outcomes and poverty and the significance of instruction in disadvantaged communities. We thus

\footnotetext{
${ }^{2}$ Hamsa Venkat directs a project similar to WMCS at the primary level, WMCP. Over time our frameworks, while sharing initial orientations to mediation and sociocultural theory, have come to differ. To assist in distinguishing these, the WMCP framework is called Mediating Primary Mathematics (MPM), and is elaborated by Venkat \& Askew (see Venkat \& Askew, under review). Our collective work up ahead will engage with similarities and differences between this and MDI as it has come to function in WMCS.
} 
understand that MDI is deeply implicated in, but only a part of a set of practices and conditions that produce poor performance across our schools. It matters deeply, how mathematical discourse in instruction supports (or not) mathematical learning. And just as context has been pivotal in the emergence and construction of MDI so too is it important to conclude by stating (the obvious) that MDI is an inherently social product, a function of where you work, with whom and on what. MDI has been shaped by the context of its emergence. It has also been shaped by and hopefully will shape the field of (mathematics) education research. Critically, it has been developed through ongoing interaction with colleagues, postdoctoral fellows and doctoral students. Key collaborators are visible in the various references to our ongoing work.

Acknowledgements This work is based on the research supported by the South African Chairs Initiative of the Department of Science and Technology, and National Research Foundation of South Africa (grant no. 71218). Any opinion, finding and conclusion or recommendation expressed in this material is that of the authors and the National Research Foundation does not accept any liability in this regard.

\section{References}

Adler, J. (2012a). Knowledge resources in and for school mathematics teaching. In G. Gueudet, B. Pepin, \& L. Trouche (Eds.), From Text to 'Lived' Resources (Vol. 7, pp. 3-22): Springer Netherlands.

Adler, J. (2012b). The research and development curve continued: Report of the wits FRF mathematics chair and the wits maths connect-Secondary (WMCS) project. Unpublished report. University of the Witwatersrand. Johannesburg.

Adler, J., \& Davis, Z. (2011). Modelling teaching in mathematics teacher education and the constitution of mathematics for teaching. In T. Rowland \& K. Ruthven (Eds.), Mathematical knowledge in teaching (Vol. 50). Dordrecht: Springer.

Adler, J., \& Pillay, V. (2017). Mathematics education in South Africa. In J. Adler \& A. Sfard (Eds.), Research for educational change: Transforming researchers' insights into improvement in mathematics teaching and learning (pp. 9-24). Abingdon: Routledge.

Adler, J., \& Ronda, E. (2015). A framework for describing mathematics discourse in instruction and interpreting differences in teaching. African Journal of Research in Mathematics, Science and Technology Education. doi:10.1080/10288457.2015.1089677

Adler, J., \& Ronda, E. (2017a). A lesson to learn from: From research insights to teaching a lesson. In J. Adler \& A. Sfard (Eds.), Research for educational change: Transforming researchers' insights into improvement in mathematics teaching and learning (pp. 133-143). Abingdon: Routledge.

Adler, J., \& Ronda, E. (2017b). Mathematical discourse in instruction matters. In J. Adler \& A. Sfard (Eds.), Research for educational change: Transforming researchers' insights into improvement in mathematics teaching and learning (pp. 64-81). Abingdon: Routledge.

Adler, J., \& Ronda, E. (in preparation). Take-up and tools: Describing and interpreting developmental shifts in mathematics teaching.

Adler, J., \& Sfard, A. (2017). (Eds.) Research for educational change: Transforming researchers' insights into improvement in mathematics teaching and learning. Abingdon: Routledge. 
Adler, J., \& Venkat, H. (2014). Teachers' mathematical discourse in instruction: Focus on examples and explanations. In M. Rollnick, H. Venkat, J. Loughran, \& M. Askew (Eds.), Exploring content knowledge for teaching science and mathematics (pp. 132-146). London: Routledge.

Alshwaikh, J., \& Adler, J. (2017a). Researchers and teachers as learners in Lesson Study. Mathematics and Technology Education (SAARMSTE), Bloemfontein, South Africa: Paper presented at the Southern African Association for Research in Science.

Alshwaikh, J., \& Adler, J. (2017b). Tensions and dilemmas as source of coherence. Paper presented at the Mathematics Education and Society (MES) Conference, Volos, Greece.

Artigue, M. (2009). The challenges of mathematics and science basic education. Paris: UNESCO.

Brown, S. (1997). Respondent comment. In S. Hegarty (Ed.), The role of research in mature education systems. Slough: National Foundation for Educational Research.

Fernandez, C. (2002). Learning from Japanese approaches to professional development: The case of lesson study. Journal of Teacher Education, 53(5), 393-405. doi:10.1177/ 002248702237394

Gamoran, A., \& Long, D. A. (2006). Equality of educational opportunity: A 40-year retrospective. Working Paper 2006-9. Wisconsin Center for Education Research (WCER) Madison, WI.

Guthrie, G. (2011). The progressive fallacy in developing countries. In favour of formalism. New York: Springer.

Hargreaves, D. (1999). Revitalising educational research: Lessons from the past and proposals for the future. Cambridge Journal of Education, 29, 239-249.

LMTP. (2011). Measuring the mathematical quality of instruction. Journal of Mathematics Teacher Education, 14, 25-47. doi:10.1007/s10857-010-9140-1

Marton, F., \& Tsui, A. B. M. (2004). Classroom discourse and the space of learning. New Jersey: Lawrence Erlbaum Associates.

Morrow, W. (2007). Learning to teach in South Africa. Pretoria: Human Science Research Council.

Ntow, F., \& Adler, J. (under review). "We have to work": Opportunities and challenges in a teacher's implementation of professional development practices.

Pournara, C., Hodgen, J., Adler, J., \& Pillay, V. (2015). Can improving teachers' knowledge of mathematics lead to gains in learners' attainment in mathematics? South African Journal of Education, 35(3), 10. doi:10.15700/saje.v35n3a1083

Reddy, V., Visser, M., Winnaar, L., Arends, F., Juan, A., Prinsloo, C. H., \& Isdale, K. (2016). TIMSS 2015: Highlights of mathematics and science achievement of grade 9 South African learners. Retrieved from Pretoria: http://www.timss-sa.org.za/download/TIMSS-Grade-9highlights.pdf

Sfard, A. (2008). Thinking as communicating human development, the growth of discourses, and mathematizing. New York: Cambridge University Press.

Shalem, Y., \& Hoadley, U. (2009). The dual economy of schooling and teacher morale in South Africa. International Studies in Sociology of Education, 19(2), 119-134. doi:10.1080/ 09620210903257224

Skemp, R. R. (1987). Relational understanding and instrumental understanding. Mathematics Teaching in the Middle School, 77, 20-26.

Skovsmose, O. (2011). An invitation to critical mathematics education. Dordrecht: Springer.

Star, S. L., \& Griesemer, J. (1989). Institutional ecology, 'translations' and boundary objects: amateurs and professionals in Berkeley's museum of vertebrate zoology, 1907-1939. Social Studies of Science, 19, 387-420.

Venkat, H., \& Adler, J. (2012). Coherence and connections in teachers' mathematical discourses in instruction. Pythagoras, 33(3). doi:10.4102/pythagoras.v33i3.188

Venkat, H., \& Adler, J. (2013). From research to teacher development in mathematics education: Creating boundary objects. Paper presented at the South African Education Research Association Conference.

Venkat, H., \& Askew, M. (under review). Mediating primary mathematics: theory, concepts and a framework for studying practice. 
Vygotsky, L. S. (1978). Mind in society: The development of higher psychological processes. Cambridge: Harvard University Press.

Watson, A., \& Mason, J. (2006). Seeing an exercise as a single mathematical object: Using variation to structure sense-making. Mathematical Thinking and Learning, 8(2), 91-111.

Open Access Except where otherwise noted, this chapter is licensed under a Creative Commons Attribution 4.0 International License. To view a copy of this license, visit http://creativecommons. org/licenses/by/4.0/. 